\title{
Does teaching a solution-focused model of counselling work? A follow-up of graduates
}

\author{
JUDI H. MILLER* \\ Health Sciences Centre, College of Education, University of Canterbury, Christchurch, New Zealand
}

\begin{abstract}
Objective: To explore the ways in which graduates of a university counsellor-education programme reflected on their career development, retained the programme's distinctive theoretical counselling model in their counselling practice and engaged in continuing professional development. The main aim was to discover whether or not teaching a solution-focused model of counselling was worthwhile. Method: A questionnaire, using primarily solution-focused type questions, was distributed to all graduates. Interest was focused on specific events, both inside and outside the training programme and beyond, that contributed to graduates' sense of development as counsellors. Results: Thirty four graduates (response rate $62 \%$ ) provided responses indicating their recognition that their sense of competence and identification as professional counsellors develops over time, and is assisted by relevant feedback and supervision from lecturers and practical counselling experience. Graduates also indicated that their favoured working model was solution-focused and that, as a framework, it provided them with opportunities to integrate other counselling models and add complementary professional development education. Conclusion: The graduates' continued use of a solution-focused model supports the view that teaching the solution-focused model is working. The findings are considered alongside four models of counsellor development and implications for counsellor-education programmes are explored.
\end{abstract}

Keywords: counsellor development, counsellor-education, professional development, critical incidents, solution-focused counselling

\section{Introduction}

Since 1992, the counsellor education programme at the University of Canterbury, Christchurch, New Zealand, has used the solution-focused Brief Therapy model, pioneered by Steve de Shazer and Insoo Kim Berg (Trepper, Dolan, McCollum, \& Nelson, 2006), to educate counselling students. This model, which is based on post-modern, social constructionist principles, is often described as an empowering, futureoriented, collaborative inquiry (Miller, Hubble, \& Duncan, 1996). Its philosophical premise includes the idea that individuals create their own reality based on the understanding of, and participation in, their previous experience (Brown \& Brooks, 1996), and that behaviour is influenced by one's social and physical environment and one's interaction within it.

Solution-focused counsellors assume that clients want to change, have the capacity to envision an alternative future, and are doing their best to work towards making that alternative future happen (Gingerich \& Eisengart, 2000). Counsellors adopt a stance of 'not knowing' and curiosity to help clients make sense of their problems, competencies, resourcefulness and possible solutions (Anderson \& Goolishian, 1992). Specific techniques include the 'miracle question', which helps clients envision a preferred future; 'exception questions', which help clients notice and describe times when their problem is reduced, or not present; and the 'scaling question', which helps clients search for and notice parts of their preferred future that may already be happening (Gingerich \& Eisengart, 2000). Guidelines for practice to help clients help themselves can be briefly stated as 'if it isn't broken, don't fix it', 'if it doesn't work, try something different' and 'if it does work, do more of it' (de Shazer, 1985).

With these guidelines in mind, the aim of this research was to discover whether or not teaching a Solution-focused model of counselling 'works' for recent graduates. The first interest was in the ways graduates reflected upon their development as counsellors and, specifically, how they described their development and if they recalled specific events in the programme that contributed to their sense of development as counsellors.

Second, in keeping with the solution-focused assertion that most change occurs outside of the counselling sessions (Berg, 1994), interest was directed at the way that recent graduates used events and experiences beyond their counsellor training to develop their professional selves. Third, in line with a principle of the counsellor-education programme that students extend their skill base, there was interest in whether recent graduates had integrated the solution-focused approach into their counselling practice and whether or not they constructed themselves as being or becoming solution-focused counsellors.

\footnotetext{
*Email: judi.miller@canterbury.ac.nz
} 


\section{J. H. Miller}

\section{Frameworks for exploration}

Since solution-focused counselling uses, essentially, a cognitive-behavioural approach to change, models of professional development used to guide this inquiry were, similarly, cognitive-behavioural in nature. From a number of possible developmental models, four were considered because of their congruence with solutionfocused principles. The first three models described below; evaluation, development and critical incidents, focus on individual self-estimates (scales) of progress or the influence of particular events (exceptions). The fourth model relates more to a curriculum focus that assumes counsellors will incorporate new learning into their personal style and experiences.

\section{An evaluation model}

While counsellor training programmes often use outcome measures, such as occupational destinations, to evaluate their curriculum, results of these are not widely available. In a study of the outcomes of counselling graduates from a New Zealand polytechnic, Cornforth and Sewell (2004) discovered that the little published material available originated from North America or the United Kingdom.

Since the aim of this current research was to explore the usefulness of teaching a solution-focused model of counselling, less focus was placed on employment outcomes, and more was placed on the ways graduates interpreted their developmental progress before and after graduation. While the effectiveness of solutionfocused counselling for clients has been surveyed (Gingerich \& Eisengart, 2000), little research focuses on the impact of training on counsellors. An exception is found in Bowles, Mackintosh and Torn (2001), who used pre- and post-training scales and a focus group interview to evaluate the impact of a short training course in solution-focused brief therapy skills on the communication skills of nurses. While the number of participants was small, results suggested that participants regarded the training as relevant and useful. After six months they reported changes in their practice, rejection of problem-orientated discourses and increased sense of adequacy.

\section{A developmental model}

Traditional constructions of career development fall into categories including Trait and Factor, Life-Span (stage), Sociological and Constructivist (Sharf, 2006). While the shortfalls in Trait and Factor approaches have given way to constructivist approaches, most literature on the career development of counsellors follows a stage-theory approach (Rønnestad \& Skovholt, 2003).

Skovholt and Rønnestad (1992) interviewed 100 American counsellors/therapists at all experience levels to construct an eight-stage model encompassing what could be described as a life-long process of professional development. In 2003, they responded to critical discussions about their model, re-read their data and collapsed the 8 stages into 6 phases. The phases are: the lay helper, the beginning student, the advanced student, the novice professional, the experienced professional and the senior professional.

While there is some debate about the usefulness of making such generalisations based on a qualitative study (Goodyear, Wertheimer, Cypers, \& Rosemond, 2003), the tidiness of their developmental model is compelling. It is, for instance, helpful to recognise that most surveys of counselling programmes are of advanced students (interns) or novice professionals (in the first years after graduation). The characteristics of Rønnestad and Skovholt's (2003) informants, who were in these phases, can be compared therefore with those of other surveys.

Two aspects mentioned by Rønnestad and Skovholt (2003) are important during the intern (advanced student) phase. These are the perceived need of students to critically assess and evaluate counselling models other than those in their training, and their frustration at the lack of opportunities to observe senior practitioners at work. According to Rønnestad and Skovholt these aspects encourage students to attend workshops for their professional development.

On the other hand, Rønnestad and Skovholt suggest that the novice professional develops through a period of more intense exploration of the self and the professional environment. Graduates in this phase appear to seek courses to compensate for perceived limitations or deficiencies in their earlier training (Rønnestad \& Skovholt, 2003).

\section{A critical incident model}

Furr and Carroll (2003) sought to identify experiences that students deemed critical to their development. A critical incident was defined as a positive or negative experience recognised by the counselling student as significant because of its influence on the student's development as a counsellor. Furr and Carroll provided 84 Masters-level counselling students with this definition and asked them to respond to an open-ended question regarding the nature of a critical incident inside, or outside, their graduate education that had influenced their development.

They categorised student responses as (a) existential issues/value conflicts; (b) cognitive development; (c) beliefs about competency; (d) professional development; (e) perceived support; (f) perceived obstacles; (g) personal growth in the counselling programme; (h) personal growth (outside the counselling programme); and (i) skill development.

The most commonly reported type of critical incident was related to events that occurred in field-based experiences. Here they noted that learning experiences involving immediate application of knowledge had a great emotional impact on the students. Students' sense of competency, development as professionals, personal growth and skill development were all challenged in these settings. An important finding in this study was the high frequency with which participants described incidents that were critical to their 
personal growth and occurred outside academic life. Their interpersonal relationships involving partners, families and friends were considered influential in their personal growth and, therefore, their development as counsellors. Furthermore, participants emphasised that private personal counselling assisted their development and life-threatening events or death of a significant person led many to re-examine their beliefs and values and their development as a counsellor.

In contrast, Bischoff, Barton, Thober and Hawley (2002) found that graduates of a Masters counselling programme considered personal stress to act as a distraction and personal therapy to have negligible impact on their development of clinical self-confidence. These researchers took the view that the primary concern for beginning counsellors is being anxious about one's competence. They therefore asked 39 recent graduates to describe noteworthy events that were associated with changes in their levels of confidence. They categorised responses into four descriptors of clinical self-confidence. These were clinical contact, which rendered both positive and negative influence depending on the length of counsellor experience; supervision and contact with peers, both of which contributed positively to clinical development and personal life stress, which participants considered detracted from increased clinical self-confidence (Bischoff et al., 2002).

\section{An integrated model}

While the above frameworks pertain to the development of the counsellor, an interest of this current research related to the resilience of the solutionfocused model as the basis of graduates' employment as counsellors. The fundamental problem associated with this question is, what constitutes solution-focused counselling? Outcome studies on the efficacy of solution-focused brief therapy highlight the difficulty in isolating essential components of the therapy.

Indeed, in one study, despite the fact that when clients and their therapists were interviewed they all described their counselling as successful by their own standards, clients' perceptions of the therapists' role differed significantly from the therapists' self-description and the philosophy of Solution-focused brief therapy (Metcalf, Thomas, Duncan, Miller, \& Hubble, 1996). This points to the premise that in this current research, only the use of the graduates' own descriptors can determine the extent to which they have continued to use solution-focused counselling in their work.

Since solution-focused counselling directs attention towards clients' strengths and needs, it is philosophically consistent for a counsellor to incorporate practices from other therapeutic approaches in their work. This integration is also encouraged for graduates of the counsellor-education programme central to the current research. Trends to integrate solution-focused work with hypnosis, narrative therapy, motivational interviewing, neuro-linguistic programming and person-centred therapy have been noted (Miller,
2006). Furthermore, Skidmore (1993); cited in Miller et al., 1996) found that while graduates of three solution-focused training centres primarily used solution-focused techniques, their treatment approaches also incorporated techniques from other approaches.

\section{Method}

\section{The researcher}

While the author has been involved in counselling, in one form or another, since the 1970s, she did not start teaching in the university counselling programme until the late 1980s. At that time the programme was based on a problem-management model. However, her symbolic interactionist background meant she was interested in the ways that people make events meaningful and she was concerned that a deficit model could be limiting. So, when she and her colleague (see acknowledgements) first discovered solution-focused brief therapy, they were very attracted to its principles.

Students, too, seemed to like its constructionist, respectful, strengths and future oriented perspective. In the programme, however, they were required to demonstrate their ability to work in a solution-focused way. The idea for this research came after questioning whether the lecturers' enthusiasm blinded them to the fact that student allegiance might be simply assessment driven. It seemed prudent to discover whether or not students continued to value and use the model after graduation. An interview-based research project was envisaged, but a questionnaire was considered an important initial investigative tool.

\section{Participants}

A questionnaire was sent to all graduates who completed the Master of Education (Certificate in Counselling) degree between 1992 and 2002. During those years enrolments averaged 9 students per year. While 64 counsellors had graduated with the Master of Education (Certificate in Counselling) contact addresses were only found for 54 (40 females and 14 males). Fifty-four questionnaires were sent out and 34 (28 female and 6 male) responses were received, a $62 \%$ response rate.

\section{Questionnaire}

The questionnaire comprised four parts. Part 1 included socio-demographic information about the year in which the counsellor graduated, their professional association affiliation, their present position and the number of hours they were currently counselling. Part 2 asked graduates to rate their development as a counsellor on a number of dimensions using a 10-point scale. Part 3 required graduates to consider specific events and experiences (critical incidents/exceptions) in the counselling programme that they considered to be helpful and/or unhelpful in developing their counselling competence. 


\section{J. H. Miller}

Respondents were given space to make their own comments and were asked to read a list of compiled factors that have been described as contributing to improving counsellor competence (Bischoff \& Barton, 2002; Rønnestad \& Skovholt, 2003), using a 10-point scale, and rate each factor according to how helpful they considered it to be for improving their counselling competence. The factors used in the questionnaire were: clinical contact, (talking with other counsellors, talking with lecturers and work completed on placements), academic requirements (course content, readings and assignments), supervision, (live supervision, supervision of video-tapes), contact with peers (talking with other students, talking with friends), and personal life stress - which was reframed as resourcefulness (thinking about my work, things I did myself).

A further question in this part of the questionnaire asked graduates to describe events outside training that were very helpful in educating them to become counsellors. This again fits with the solution-focused principle that much client change occurs as a result of extra-therapeutic factors (Lambert \& Barley, 2001). Part 4 of the questionnaire invited the graduates to list significant formal professional development activities in which they had engaged during the previous 12 months.

The questionnaire was piloted with two counselling students who were not part of the survey population. Minor changes were made to clarify the meaning of some questions.

\section{Ethical considerations}

The researcher was aware that, because the counselling community is small and lecturers continue to have contact with graduates, participants might feel duty bound to support the work of their lecturers. For this reason, emphasis was made in all communication that participation was voluntary and anonymous. The project and procedures were approved by the University of Canterbury Human Ethics Approval Committee.

\section{Results}

\section{Socio-demographic data}

Year completed. The majority of responses received were from counsellors who graduated between 1996 and 2002. Only five completed questionnaires were from counsellors who graduated between 1992 and
1995 inclusive. Each year, thereafter, at least half of the graduates responded.

Professional Association membership. Eighteen respondents $(52 \%)$ were full members of the New Zealand Association of Counsellors and 5 (15\%) were applicant members. Other associations represented included the British Association of Counselling and Psychotherapy (1), The New Zealand Psychological Society (1), New Zealand Nurses Association (3), and the Post Primary Teachers Association (3).

Hours of counselling. The majority of counsellors worked in counselling for more than 15 hours per week. Eleven (32\%) counsellors worked 14 hours or less per week; ten (29\%) worked 15-20 hours per week and 13 (38\%) worked more than 20 hours per week.

\section{Counsellor development}

Counsellors were asked to use a 10-point scale to make self-estimates of their development on a number of counsellor dimensions during three periods of their career: (1) before their training, (2) at graduation and (3) right now. On the scale 1 equated to 'extremely naïve' or 'undeveloped' and 10 equated to 'extremely knowledgeable' or 'well developed'. The intermediate scores did not carry a label. This is in keeping with scaling practices in solution-focused counselling. Table I presents the mean values of their responses.

Data in Table I demonstrate that in every case, there is an increase in development of attributes from 'before training' to 'upon completion of training. The largest increase is in the increased level of solution-focused skills. Also recorded is an increase in each attribute from 'upon completion of training' to 'now'. These findings are not surprising, but, in solution-focused terms, it is useful for graduates to acknowledge perceived change as this increases the likelihood of further development.

\section{Professional development after graduation}

Whereas much of the questionnaire asked respondents to comment on their development during their training, Part 4 of the questionnaire pertained to professional development experiences after graduation. Eighty five per cent of graduates said that they

Table I. Mean values of counsellor self-estimates of their development where ' 1 ' equates to undeveloped and '10' equates to well developed.

\begin{tabular}{lcc}
\hline Area of counsellor development & Before training & At graduation \\
\hline Personal values related to counselling & 4.9 & 7.2 \\
Professional values related to counselling & 4.4 & 7.3 \\
Sense of being a professional counsellor & 3.3 & 6.7 \\
Growth as a person & 5.2 & 7.0 \\
Personal growth related to being a counsellor & 4.1 & 6.7 \\
Level of general counselling skills & 3.8 & 6.5 \\
Level of solution-focused skills & 1.4 & 8.4 \\
\hline
\end{tabular}


had engaged in a range of further training and study over the previous 12 months. Training included academic study $(n=4)$, training for specific client issue/context $(n=39)$, Counselling Association seminars/conferences $(n=10)$, and training in specific modalities $(n=13)$. This high rate of professional development is to be expected when most professional associations mandate it.

\section{Critical incidents}

Incidents during training. In this section of the questionnaire, respondents used a 10-point scale to rate factors deemed useful or important for improving their counselling competence. They were also invited to write comments to qualify their choices. Table ॥ indicates that, while the majority of respondents rated all factors highly, there were some slight discrepancies.

The majority of participants rated work done on placements the highest. Comments qualifying this high rating included: 'this really gives you a chance to put into practice what you have learned' and 'practical work in my placement shaped me', and 'very valuable'. Closely associated with this factor, another highly rated factor was talking with counsellors. Here comments included: 'boosted my confidence' and 'working alongside other counsellors and gaining insight into their models and how they apply them ... was valuable'.

Two factors that were also rated highly related to self-resourcefulness. Comments associated with thinking about my work included: 'critical reflection on what I was doing[helped]' and 'it is always important to reflect on your work and ask how I could do this better?'. It is possible that the high rating given to assignments I completed also reflected selfresourcefulness. Comments included: 'especially the early one [assignment] on my counselling world view/philosophy' and 'received great value out of this work - uniquely mine' and 'produced useful resources and good for reflection'. There were, however, some negative comments made about assignments:
'I struggled to find the relevance of some' and 'only the world view assignment rates highly'.

An interesting range of rating responses for supervision contributed to a middle rating for both live (in vivo) supervision and supervision of video-tapes. Comments associated with this factor ranged from 'positive comments [of lecturers] boosted confidence' and 'the most help!' to 'hard, but more valuable than expected' and 'problematic, I felt they were intrusive and too scary to get much out of'. Related to this, when graduates were asked, in the questionnaire to think about critical incidents that were helpful during training, some made the following comments:

- Video analysis with tutors - feeling safe to make mistakes and get positive feedback or encouragement for improvement.

- The first live supervision with a lecturer present. I was really struggling with all the new concepts. The lecturer helped me formulate the feedback to the client [solution-focused skill] and it worked so well. The client had changed dramatically by the next session.

- Videos (delayed supervision with lecturer) were extremely stressful but extremely useful for learning.

Incidents during but outside training. In keeping with the solution-focused principle that most change for clients occurs outside the counselling interview, respondents were given space in the questionnaire to describe events that occurred outside their training that they considered were very helpful in their development as counsellors. The main events mentioned related to clinical contact, contact with peers and personal life events.

Clinical contact. Ten graduates (29\%) mentioned the importance of client contact for their development. Comments included: 'clients are our most important teachers' and 'every single new client I meet [helps my development]'. Some comments related specifically to

Table II. Mean values assigned by counsellors to factors during training that improved counsellor competence where '1' equates to completely unimportant/not useful and ' 10 ' equates to extremely important/useful.

\begin{tabular}{|c|c|c|}
\hline Grouped theme* & Factors** & Mean rating \\
\hline Clinical contact & Work conducted on placement & 9 \\
\hline Clinical contact & Talking with lecturers & 8.1 \\
\hline Clinical contact & Talking with counsellors & 8.3 \\
\hline Resourcefulness & Things I did myself & 8.2 \\
\hline Resourcefulness & Thinking about my work & 8.3 \\
\hline Supervision & Live supervision with lecturer & 7.6 \\
\hline Supervision & Supervision of videotapes with lecturer & 7.9 \\
\hline Academic requirements & Specific course content & 7.6 \\
\hline Academic requirements & Assigned readings & 7.4 \\
\hline Academic requirements & Assignments I completed & 8.1 \\
\hline Academic requirements & Library research and reading & 7.5 \\
\hline Contact with peers & Talking with other students & 7.9 \\
\hline Contact with peers & Talking with friends & 6.3 \\
\hline
\end{tabular}

*This column was not included in the questionnaire.

**The order in which these factors were presented to respondents differed from that described in this table. 


\section{J. H. Miller}

incidents that increased counsellors' allegiance to the solution-focused model. One wrote: 'I remember using solution-focused questions in a first session with a couple. In the second session they reported that the session had been very helpful and much better for them than the agency they had been to previously'. Another wrote: 'A client I was working with suddenly responded to my feedback by changing her life in a very positive manner'.

Nine counsellors (26\%) mentioned that specific counsellor modality trainings they attended helped their own development. One stated: 'I attended a narrative therapy workshop towards the end of my internship and that stimulated my interest in 'stories' and language and it fitted well with my solutionfocused ideas and methods'.

Contact with peers. Ten graduates (29\%) considered that their attendance at regional or national counsellor meetings was helpful. One stated:

Their [other counsellors'] interest and encouragement fuelled my desire to do well in the Master of Education course and partly influenced my decision to aim for a distinction level of achievement.

Personal life stress. Eight counsellors commented on their general life experience; for example, nursing training prior to counsellor training, and seven remarked that being a parent was levelling and helpful in their own development. Seven remarked that the experience of resolving their own trauma, for example death of a significant person, and six considered that having their own personal therapy was helpful.

\section{Integration of solution-focused approach into counselling practice}

In response to the question, to what extent are you still using solution-focused counselling?, 27 graduates (79\%) noted that their main approach or framework was solution-focused. Many indicated that they had integrated the solution-focused approach with other counselling models. For example:

I still use solution-focused primarily as a framework and philosophical base ... in terms of specific techniques, I use a variety from solution-focused, cognitive behavioural therapy, systems and narrative mostly whatever fits the client's own framework.

Solution-focused counselling still provides the framework for the work I do ... however, I also have found aspects of transactional analysis, gestalt, family history, awareness of cross-cultural issues to be helpful.

I find that solution-focused works best for children, adolescents and families. Focusing on their own goals, own skills, and own motivations, gives the clients power and control and feels good for me as facilitator. And another wrote: I use solutionfocused therapy as a framework for all my counselling - establishing strengths and skills and planning the client's counselling goals and the various steps needed to move towards the goals. I use cognitive behavioural therapy for the steps to move toward the goals.

When the rate of solution-focused use was correlated with number of years since graduation, there was little variation. Of the 27 graduates who indicated that they used solution-focused counselling more than $50 \%$ of the time, ten had graduated up to two years before responding, seven had graduated up to four years before responding, six graduated up to six years and four up to 10 years before responding to the questionnaire. Of the seven graduates who indicated that they used solution-focused counselling less than $50 \%$, three had graduated up to four years before answering, and two up to eight years; two were not currently counselling.

\section{Discussion}

The original aim of this research was to gain some insight to graduate views of the relevance and usefulness of their training for evaluation purposes. Specific aims were to describe key factors that were perceived as important or useful inside, outside and beyond the counsellor-education programme.

\section{Counsellor views}

In terms of the developmental model, most respondents in this study would be situated in the novice professional phase, but some questions asked them to recall events in their student phases. Results recorded in Table 1 indicate that graduates have a retrospective sense of their own development of counsellor attributes. Clearly elapsed time and experience help counsellors feel more confident about their use of solution-focused counselling skills, and about themselves as counsellors. Just as the use of a 10-point scale in solution-focused counselling helps clients to recognise their own developmental shifts, the use of a 10-point scale for graduates in this research may have helped them reflect on and recognise their developing competence.

In terms of the importance of critical incidents to the development of counsellors, many of the incidents remembered and mentioned by participants in this study supported those described by Furr and Carroll (2003) and Bischoff et al. (2002). In contrast to the finding of Rønnestad and Skovholt (2003) where students expressed frustration at not being able to observe senior counsellors, the counsellors rated their experience in placements as the most influential with many noting how helpful it was for them to observe senior counsellors. Also, counsellors frequently mentioned critical incidents that occurred outside academic 
life as influential. This finding could be considered alongside 'common factors' research (Lambert \& Barley, 2001) suggesting that extra-therapeutic factors contribute most to client change. Most respondents noted that, whether the event was positive or negative, they thought it had a positive influence on their development.

Graduates also considered factors that were important to their development included their ability during training to reflect on issues and help themselves, to complete some assignments and to engage in supervision, live or delayed, of their solutionfocused practice. It is particularly important to note that many counsellors recognise the considerable influence that their clients have on their development. A solution-focused principle is that counsellors help clients to recognise their own strengths, successes, resourcefulness and expertise. When counsellors say that their clients are some of their best teachers, this principle appears to be 'working' in practice.

\section{Further research and implications for counsellor training programmes}

The positive reflections of participating counsellors suggest that teaching a solution-focused approach to counselling is 'working'. Furthermore, it is suggested that solution-focused principles applicable to clients might also be applied to counsellors in training. Such principles include the ideas that: change is inevitable, conversations are transformative, expectancy of client success encourages positive change, perceived competence encourages positive change and self-helpfulness encourages maintenance of change (Miller, 2006).

It would be useful, therefore, for lecturers in any programme to establish expectancy, at the outset, that students will increase their sense of competence and confidence by practising in their field placements. Another useful strategy would be to include a self-rating development scale at the beginning and end of the programme for students to observe their own level of change. Furthermore, students should be encouraged to increase their self-helpfulness by seeking out opportunities to extend their knowledge and addressing perceived needs with appropriate professional development. Each of these suggestions could be developed into a future research endeavour.

An important support for the transformative nature of conversations is the finding (Table II) that counsellors learn by talking. All counsellor-educators could highlight for students the potential to learn from clients, counsellors and supervisors. In this present research, reactions to receiving live and delayed supervision were varied. Additional research on the way(s) in which graduates use supervision to perceive their competence and improve their practice could be included in a qualitative study using semi-structured interviews. Findings from such a study would also inform counsellor-educators.

\section{Limitations}

First, the generalisability of the findings is limited as the research focused on only one training programme, so no comparative data are available. While the questionnaire response rate $(62 \%)$ is reasonable, the sample size is small and the discrepancies in some responses can only be interpreted, not tested for significance. Furthermore, while it might be assumed that graduates who did not return their questionnaires were not employed as counsellors, this cannot be verified.

Second, the use of self-reports of past events introduces potential biases due to retrospective shift (Drennan \& Hyde, 2008) and the desirability to please the lecturers. While the anonymity of the survey may have reduced this latter factor, it cannot be ignored. Since one aim of this research was to allow counsellors to express subjective experiences of their development, their responses still have merit. A follow-up interview would have strengthened the study.

\section{Conclusion}

Despite it limitations, this research supports the view that counsellors' sense of competence and identification as professional counsellors develops over time. The research does not necessarily support the view that this development follows a linear phase model. Rather, it provides some evidence that individuals create their own understanding of their own development through reflection on their interaction with their educative experiences. The research also supports the view that the constructs of personal and professional development of counsellors overlap; a view that requires further exploration in terms of evaluating counsellor competence.

The original question posed for this research was 'does teaching a solution-focused model of counselling "work" for recent graduates?' Given that a premise of the solution-focused approach is that the client determines whether or not their counselling 'works' for them, this research question may only be fully answered when graduates, and some of their clients, are interviewed in depth about their experiences.

Nevertheless, presuming that one indicator of 'working' is that the graduates continue to use a predominantly solution-focused approach in their counselling, it appears that the course does 'work'. Nearly all of the graduates have constructed themselves as being life-long learners and counsellors who use a solution-focused framework to shape their work.

\section{Acknowledgements}

I wish to thank my, now retired, colleague Bob Manthei who worked with me at the developmental phase of this research to gain ethics approval, construct and pilot the questionnaire. I appreciate the willingness with which graduates responded to our request for information. 


\section{Biographical Note}

Judi H. Miller is an associate professor and the coordinator of the University of Canterbury counselling programme. Her interest is in the professionalisation of counselling, evaluation of counsellor effectiveness and the use of solution-focused counselling in careers work.

\section{References}

Anderson, H., \& Goolishian, H. (1992). The client is the expert: A not-knowing approach to therapy. In S. McNamee \& K. J Gergen (Eds.), Therapy as social construction. London: Sage.

Berg, I.K. (1994). Family based services: A solution-focused approach. New York: Norton.

Bischoff, R.J., Barton, M., Thoeber, J., \& Hawley, R. (2002). Events and experiences impacting the development of clinical self confidence: A study of the first year of client contact. Journal of Marital and Family Therapy, 28 (3), 371-382.

Bowles, N., Mackintosh, C., \& Torn, A. (2001). Nurses' communication skills: An evaluation of the impact of solution focused communication training. Journal of Advanced Nursing, 36 (3), 347-354.

Brown, D., \& Brooks, L. (1996). Introduction to theories of career development and choice. In D. Brown \& L. Brooks (Eds.), Career choice and development (3rd edn, pp. 1-30). San Francisco, CA: Jossey-Bass.

Cornforth, S., \& Sewell, S. (2004). Where have they gone? What are they doing? The profiles and destinations of counselling graduates, 1997-2002. New Zealand Journal of Counselling, 25 (1), 31-47.

de Shazer, S. (1985). Keys to solution in brief therapy. New York: Norton.

Drennan, J., \& Hyde, A. (2008). Controlling response shift bias: The use of retrospective Pre-test design in the evaluation of a Master's programme. Assessment \& Evaluation in Higher Education, 33 (6), 699-709.
Furr, S.R., \& Carroll, J.J. (2003). Critical incidents in student counselor development. Journal of Counseling and Development, 81, 483-489.

Gingerich, W.J., \& Eisengart, S. (2000). Solution-focused brief therapy: A review of the outcome research. Family Process, 39 (4), 477-498.

Goodyear, R.K., Wertheimer, A., Cypers, S., \& Rosemond, M. (2003). Refining the map of counselor development journey: Response to Rønnestad and Skovholt. Journal of Counseling and Development, 30 (1), 73-80.

Lambert, M.J., \& Barley, B.E. (2001). Research summary on the therapeutic relationship and psychology outcome. Psychology, 38, 357-361.

Metcalf, L., Thomas, F.N., Duncan, B.L., Miller, S.D., \& Hubble, M.A. (1996). What works in solution-focused brief therapy. In S. D. Miller, M. A. Hubble \& B. L. Duncan (Eds.), Handbook of solution-focused brief therapy. San Francisco, CA: Jossey-Bass.

Miller, J.H. (2006). Using a solution-building approach in career counselling. In M. McMahon \& W. Patton (Eds.), Career counselling: Constructivist approaches. Abingdon: Routledge.

Miller, S.D., Hubble, M.A., \& Duncan, B.L. (1996). Handbook of solution-focused brief therapy. San Francisco, CA: Jossey-Bass.

Rønnestad, M.H., \& Skovholt, T.M. (2003). The journey of the counsellor and therapist: Research findings and perspectives on professional development. Journal of Counseling and Development, 30 (1), 5-44.

Sharf, R.S. (2006). Applying career development theory to counseling. Belmont, CA: Brookes/Cole.

Skidmore, J.E. (1993). A follow-up of therapists trained in the use of the solution-focused brief therapy model. Doctoral dissertation, University of South Dakota (cited in Miller et al., 1996.)

Skovholt, T.M., \& Rønnestad, M.H. (1992). Themes in therapist and counselor development. Journal of Counseling and Development, 70, 505-515.

Trepper, T.S., Dolan, Y., McCollum, E.E., \& Nelson, T. (2006). Steve de Shazer and the future of solution-focused therapy. Journal of Marital and Family Therapy, 32 (2), 133-140.
735 